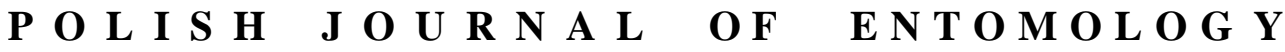

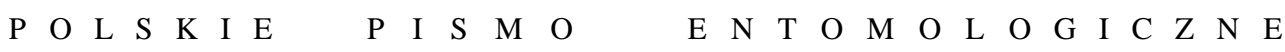

VOL. 87: 101-118

Lublin

30 June 2018

DOI: $10.2478 /$ pjen-2018-0008

\section{A new species of the genus Acrophylla GRAY, 1835 from Larat Island, Indonesia (Phasmatodea: Anareolatae: Phasmatidae: Phasmatinae: Phasmatini)}

\author{
OSKAR V. CONLE ${ }^{1 *}$, FRANK H. HENNEMANN ${ }^{2}$ \\ ${ }^{1}$ Am Freischütz 16, 47058 Duisburg, Germany \\ ${ }^{2}$ Reiboldstrasse 11, 67251 Freinsheim, Germany
}

\begin{abstract}
The new species Acrophylla bhaskarai sp. n. from Larat Island, Indonesia, is described from both sexes and the egg. It is the second species of the genus Acrophylla GRAY, 1835 known from outside Australia and the first record of the genus from Wallacea. The discovery raises the number of genera of the tribe Phasmatini known to occur within the boundaries of Wallacea to five.
\end{abstract}

KEY WORDS: Phasmatodea, Phasmatidae, Phasmatini, Acrophylla, Wallacea, new species.

\section{INTRODUCTION}

A recent study of the members of the tribe Phasmatini GRAY, 1835 that occur within the boundaries of Wallacea by HENNEMANN et al. (2015) listed four different genera. Specimens of another apparently new species have recently become available from the Island of Larat, the northernmost of the Tanimbar Islands in the extreme south-east of Wallacea. These have proven to belong to the genus Acrophylla GRAY, 1835, which has previously not been encountered in Wallacea. Acrophylla is a principally Australian genus and currently contains eight species, six of which are endemic to Australia. One species, $A$. maindroni (REDTENBACHER, 1908), was described from New Guinea and one questionable species was described from southern China (CHEN \& HE 2001). The latter species, namely

\footnotetext{
*Corresponding author: conle@phasmatodea.de
} 
Acrophylla sichuanensis CHEN \& HE, 2001, is believed to be not congeneric, since it is most unlikely that Acrophylla occurs in China (HENNEMANN et al. 2008: 41). The current discovery adds a fifth genus of the tribe Phasmatini to the Wallacean fauna. Further genera that have several species in Australia but also occur within Wallacea are Anchiale STÅL, 1875 and Eurycnema SeRvilLe, 1838 (Hennemann et al. 2015). The other two genera have their distributions either completely restricted to Wallacea (Paracyphocrania REDTENBACHER, 1908)) or defined to Wallacea and New Guinea (Phasma Lichtenstein, 1796).

\section{MATERIALS AND METHODS}

The material used for this study is dried and pinned; females have been eviscerated and stuffed with cotton. The colouration is described from dried specimens, to which attention needs to be drawn, as the insects may have changed colour due to preservation. All eggs examined were already laid and thus fully developed. The insects and eggs were examined using an entomological lens with $4 \mathrm{x}$ magnification and a Zeiss Stemi SV 6 stereomicroscope. Eggs were examined at $5 \mathrm{x}$ magnification. Measurements were taken using a long ruler or a digital calliper and are given to $0.1 \mathrm{~mm}$. Body lengths of females given in the captions of the illustrations include the subgenital plate. The terminology used for the descriptions of external and internal egg structures follows that of CLARK-SELLICK (1997). The data of the specimens examined are reproduced exactly as on the labels, and labels are separated by a semicolon.

\section{Abbreviations:}

- ZSMC - State Zoological collections, Munich, Germany;

- OC - Private Collection of Oskar CONLE, Germany;

- EB - Private Collection of Edy BHASKARA, Java, Indonesia;

- HT - Holotype;

- PT - Paratype.

RESULTS

\section{Acrophylla GRAY, 1835}

Type-species: Phasma titan MACLEAY, 1826 by subsequent designation of KIRBY 1904: 388. 
Acrophylla GRAY, 1835: 38.

Vetilia STÅL, 1875: 36, 84. (Synonymised by BROCK \& HASENPUSCH 2007: 72)

Not: Acrophylla CHEN \& HE, 2001: 8.

Not: Acrophylla CHEN \& HE, 2008: 343.

This principally Australian genus has been treated by BROCK \& HASENPUSCH (2007, 2009), who also presented a list of species. A discussion on the questionable $A$. sichuanensis CHEN \& HE, 2001 from China was provided by HENNEMANN et al. (2008). Only two of the eight known species occur outside Australia: these are A. maindroni (REDTENBACHER, 1908) from New Guinea and the here newly described Wallacean $A$. bhaskarai sp. n. from Larat Island, Indonesia.

Acrophylla is very closely related to Anchiale STÅL, 1875, which apart from several Papuan and Australian species has two known species in Wallacea, Anchiale buruense Hennemann, Conle \& SuZUKi, 2015 and Anchiale maculata (Olivier, 1792), which is the latest one widely distributed in the Maluku Islands, Peleng Island and Kei Islands (HENNEMANN et al. 2015). The heavily tuberculose mesonotum of the males and the elongate, apically pointed sugbenital plate of the females that extends considerably over the apex of the abdomen readily distinguishes the newly described representative of Acrophylla from the two Wallacean species of Anchiale.

\section{Acrophylla bhaskarai sp. n.}

\section{Material examined}

Holotype: female: Indonesia: Tanimbar Islands, Larat Island, leg. Edy BHASKARA 10.2016; OC-0427-1; Ex Coll. O. CONLE [ZSMC].

Paratypes: 5 females, 2 males, 3 eggs: Indonesia: Tanimbar Islands, Larat Island, leg. Edy BHASKARA10.2016 [OC, No. 0427-2 - 0427-11]; 2 females, 1 egg: Indonesia: Tanimbar Islands, Larat Island, leg. Edy BHASKARA 10.2016 [EB].

\section{Differential diagnosis}

This new species is very similar and closely related to Acrophylla wuelfingi (REDTENBACHER, 1908) from northern Queensland, Australia, but clearly differs in the egg morphology and further features of the adult insects. Females can be distinguished from those of $A$. wuelfingi by their somewhat shorter subgenital plate (Fig. 4), which does not project over the apex of the abdomen by more than $1 / 3$, the slightly shorter alae (Fig. 2) reaching at best the centre of abdominal segment $\mathrm{V}$, and the comparatively less prominent 
tubercles of the meso- and metathorax. Males differ in the slightly more slender body (metathorax slightly wider than head; almost $2 \mathrm{x}$ wider than head in A. wuelfingi) and relatively longer mesothorax (Fig. 8), the granulose metasternum (smooth in A. wuelfingi, Fig. 8) and the somewhat shorter and differently coloured alae, which have the anal fan darker grey, all veins distinctly marked in brown and the basal portion of the costal region bright red (Fig. 6). The most significant difference is in the eggs. These are not simply ovoid as in A. wuelfingi but have a distinct polar mound, a concave ventral surface, a larger opercular angle, a much more slender micropylar plate, a smaller capitulum and a much less developed pattern of the capsule and operculum (Fig. 2).

\section{Etymology}

This new species is named after its collector, Edy Bhaskara, from Indonesia, Eastern Java, Malang.

\section{Description}

\section{Female}

Fairly large for the genus, with an elongate and lanceolate subgenital plate and very small cerci (Fig. 1). General colouration ranging from greenish pale brown, through ochre to mid brown. Antennae greyish mid to dull brown. Eyes dull reddish brown in preserved specimens. Granules of mesothorax, metapleurae and metasternum mid to dull green. Subgenital plate often with a washed white to pale whitish green sub-basal marking. Costal area of alae and tegmina mid brown to ochraceous green, furnished with irregular pale yellowish speckles and markings; basal portion red. Anal fan of alae dark brown with a variable number of irregularly dispersed rounded translucent spots (Fig. 2).

Head: Ovoid, about 1.6x longer than wide and tapering very slightly in the posterior portion, vertex gently rounded and smooth. Frons gently convex and with vestigial ocelli. Eyes almost circular in outline, convex and more than three times shorter than cheeks. Antennae slender and slightly projecting over apex of profemora, consisting of 27 segments. Scapus slightly compressed dorsoventrally, rectangular and about $1.3 x$ longer than wide. Pedicellus cylindrical and less than half the length of scapus. Segment III slightly longer than pedicellus, IV much shorter, the following slightly increasing, and the terminal seven segments (except terminal antennomere) slightly decreasing in length.

Thorax: Pronotum slightly narrower than head, with the lateral margins gently concave. Transverse median sulcus moderately impressed and gently rounded. Mesothorax variable in length, 3.5-4.4x longer than pronotum, and somewhat swollen pre-medially. Mesonotum irregularly set with a variable number of blunt, conical tubercles. Meso- and metasternum 


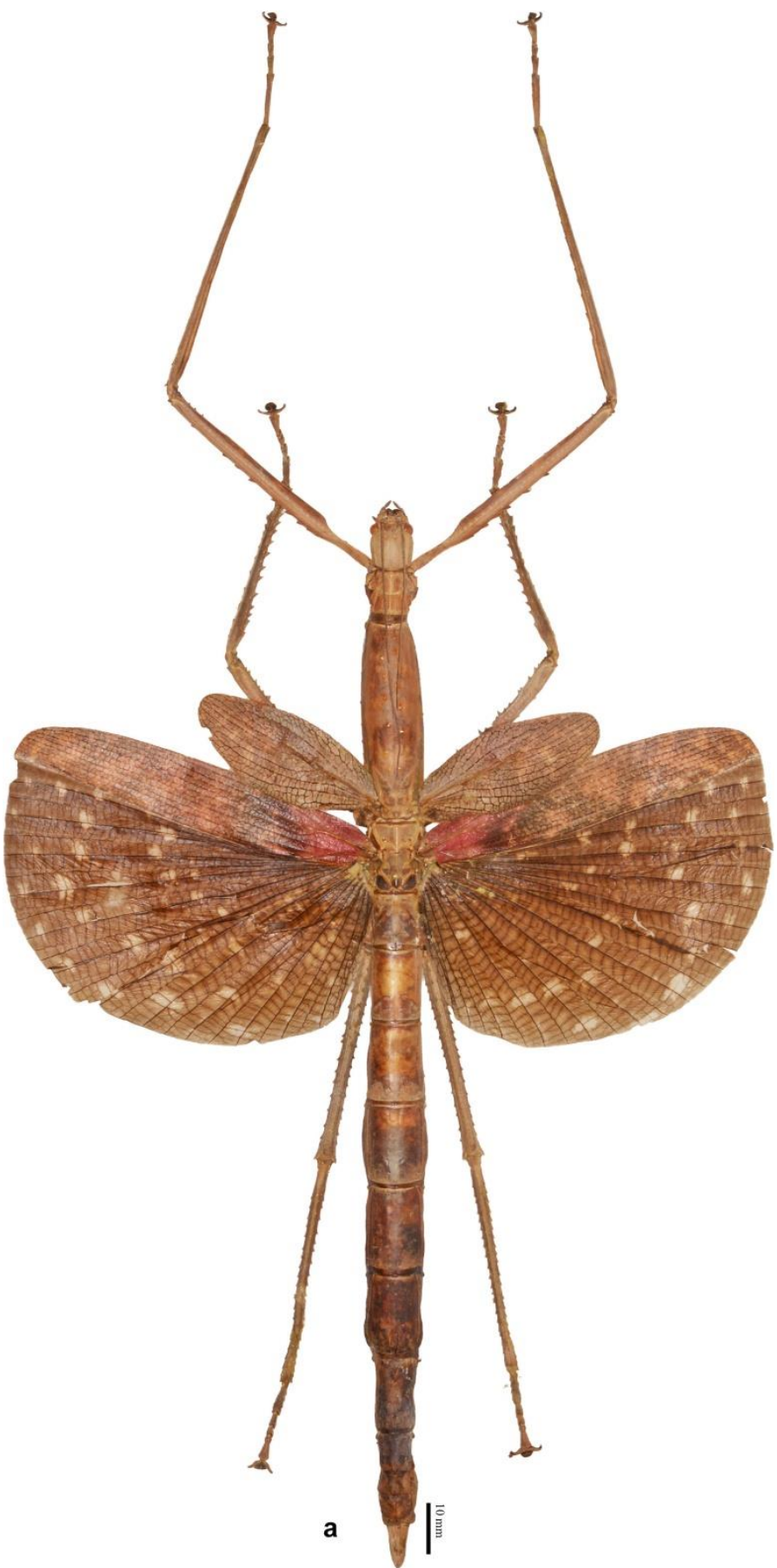

Fig. 1. Habitus of a female of Acrophylla bhaskarai sp. n.: a. Acrophylla bhaskarai (HT). Dorsal. 

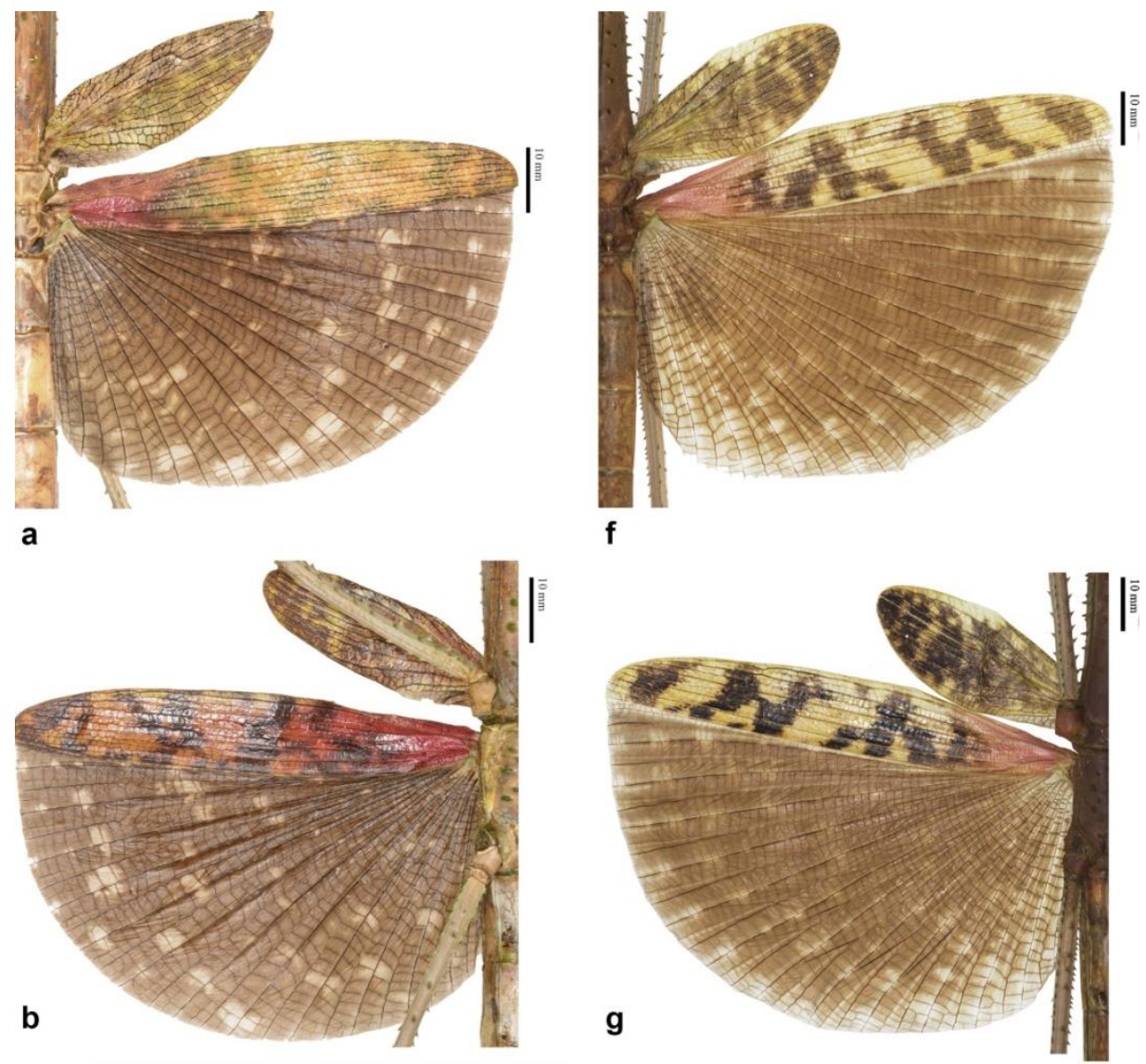

b

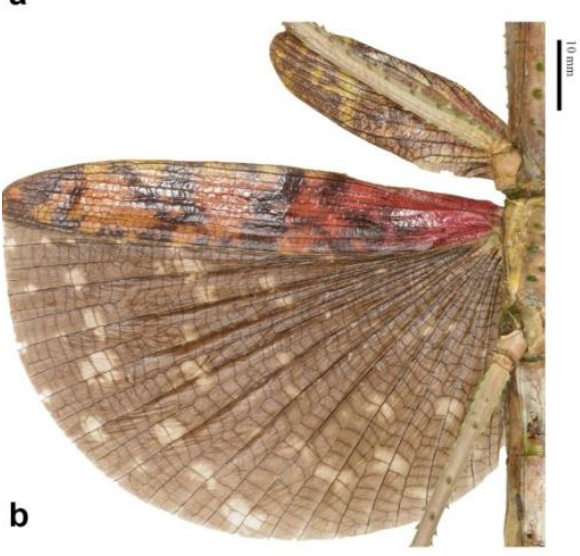

g
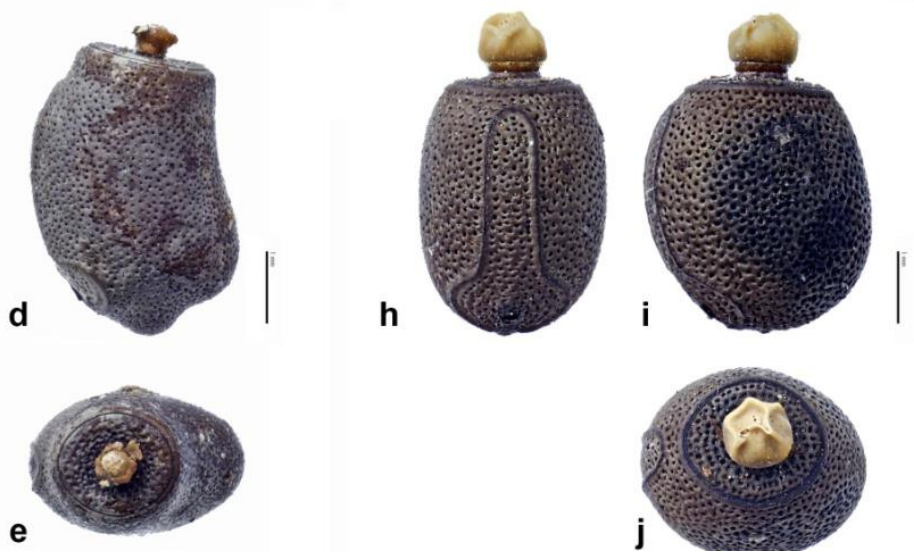

Fig. 2. Comparison of eggs and wings in females of Acrophylla wuelfingi (REDTENBACHER, 1908) and Acrophylla bhaskarai sp. n.: a-e. Acrophylla bhaskarai (PT). Wings. a. Dorsal; b. Ventral. Eggs. c. Dorsal; d. Lateral; e. Frontal. f-j. Acrophylla wuelfingi. Wings. f. Dorsal; g. Ventral. Eggs. h. Dorsal; i. Lateral; j. Frontal. 


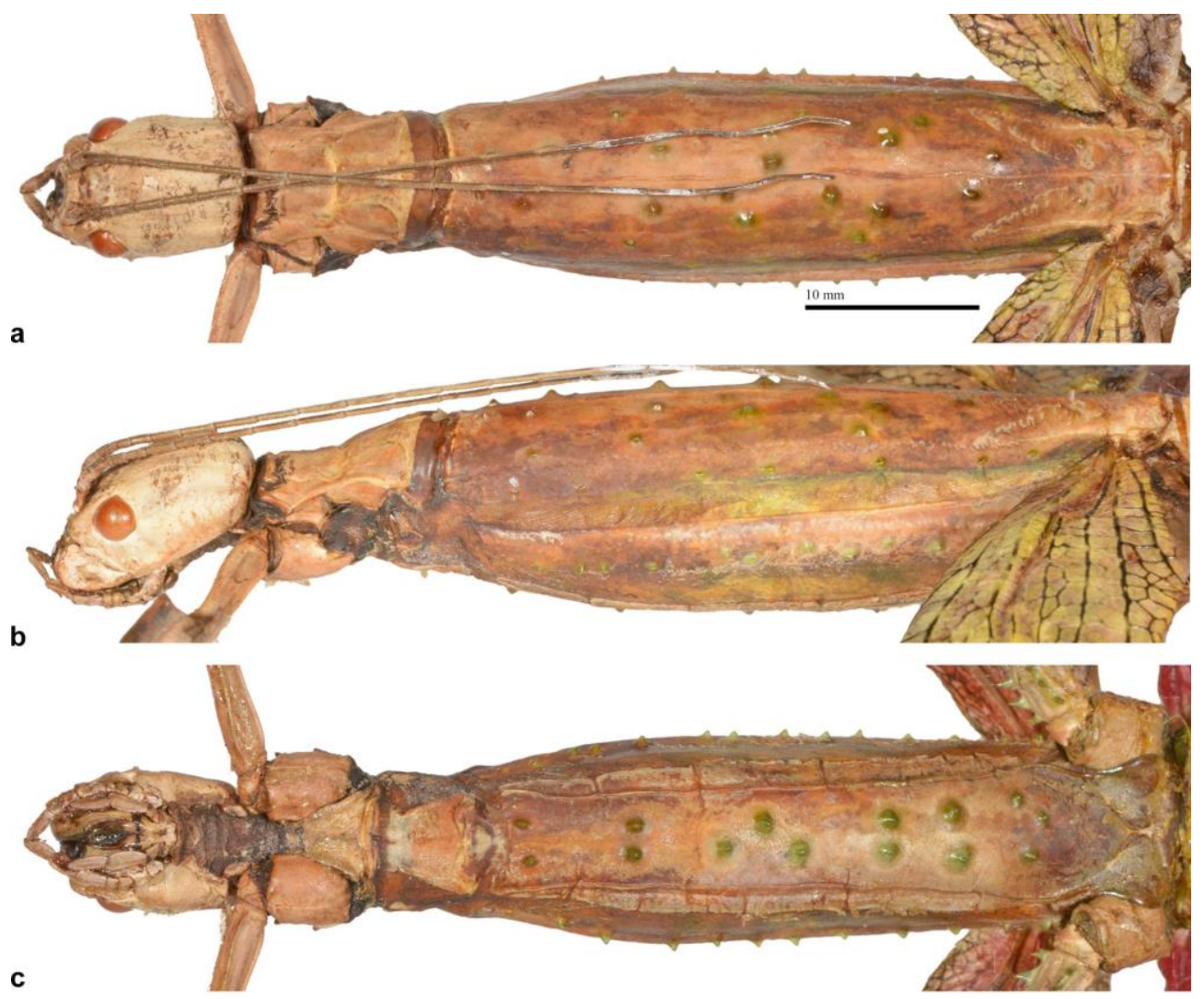

Fig. 3. Head, prothorax and metathorax of a female of Acrophylla bhaskarai sp. $\mathbf{n}$. a-c. Acrophylla bhaskarai (PT). a. Dorsal; b. Lateral; c. Ventral.

tuberculose (Fig. 3). Tegmina ovate, projecting over posterior margin of median segment and with a small, roundly conical hump pre-medially. Alae roughly reaching posterior margin of abdominal segment $\mathrm{V}$.

Legs: All slender and relatively long, with most carinae dentate or serrate to a variable degree. Profemora longer than mesothorax; mesofemora roughly equal to or slightly longer than mesothorax and Metafemora, almost reaching the posterior margin of abdominal segment IV. Posterodorsal carina of profemora distinctly raised and serrate, the posteroventral carina set with 11 distinct triangular teeth. Protibiae unarmed except for fairly small serrations on posteroventral carina. Meso- and metafemora trapezoidal in crosssection, with dorsal carinae slightly approaching each other. The two outer ventral carinae distinctly dentate, the two dorsal carinae only with a few small teeth, which decrease in size towards the apex of femur or even disappear in the apical half on metafemora. Meso- and 
metatibiae with all carinae serrate but serrations less distinct on dorsal carinae; probasitarsi elongate and considerably longer than following three tarsomeres combined; unarmed. Meso- and metabasitarsi clearly longer than the following three tarsomeres combined with all carinae minutely dentate. Hind legs never reaching over apex of abdomen. See Table 1 for measurements.

Table 1. Measurements [mm] of Acrophylla bhaskarai sp. n. Abbreviations: TL - total length, $\mathrm{L}$ - length, $\mathrm{W}$ - width, $\mathrm{H}$ - height, OS $\varnothing$ - operculum small $\varnothing$, OL $\varnothing$ - operculum large $\varnothing, \mathrm{OL}-$ operculum length.

\begin{tabular}{lccccc}
\hline Eggs: & \multicolumn{1}{c}{ W } & H & OS Ø & OL Ø & OL \\
\hline TL & L & W & 1.49 & 2.01 & $0.31-0.59$ \\
\hline $4.51-4.53$ & $4.18-4.2$ & $2.65-2.69$ & $2.05-2.09$ & & \\
\hline Imagines: & & & & \\
\hline \multicolumn{1}{c}{ Feature } & $\begin{array}{c}\text { Female holotype } \\
\text { [ZSMC] }\end{array}$ & $\begin{array}{c}\text { Females paratypes } \\
\text { [Coll. OC] }\end{array}$ & $\begin{array}{c}\text { Males paratypes } \\
\text { [Coll. OC] }\end{array}$ \\
\hline Body length & 207.0 & $198.0-219.0$ & $114.5-119.5$ \\
$\quad$ (incl. subgenital plate): & & & \\
Pronotum: & 10.5 & $8.9-13.0$ & $4.3-4.8$ \\
Mesonotum: & 38.6 & $34.2-42.5$ & $19.4-19.8$ \\
Metanotum: & 13.4 & $12.3-14.0$ & 7.1 \\
Median segment: & 11.0 & $10.4-12.5$ & $7.1-7.3$ \\
Profemora: & 51.0 & $40.8-52.9$ & $32.4-33.9$ \\
Mesofemora: & 35.7 & $29.9-37.6$ & $25.7-25.8$ \\
Metafemora: & 43.4 & $35.1-46.2$ & $32.8-33.3$ \\
Protibiae: & 55.5 & $44.1-62.0$ & $38.4-42.8$ \\
Mesotibiae: & 35.3 & $27.9-38.0$ & $24.0-26.6$ \\
Metatibiae: & 45.7 & $36.0-48.3$ & $32.8-37.6$ \\
Antennae: & 51.0 & $>10.3-56.9$ & $49.1-55.7$ \\
\hline
\end{tabular}

Abdomen: Abdomen excluding median segment considerably longer than head and thorax combined. Median segment slightly shorter than metanotum and segment II slightly longer than median segment. II-IV slightly increasing in length, IV and V roughly equal in length and longest segments, VI-X decidedly decreasing in length; IV and V roughly $1.5 x$ longer than wide. VIII only about 1/2 the length of VII. Anal segment indistinctly longer than IX and with a slight longitudinal median carina; the posterior margin broadly rounded. 
a
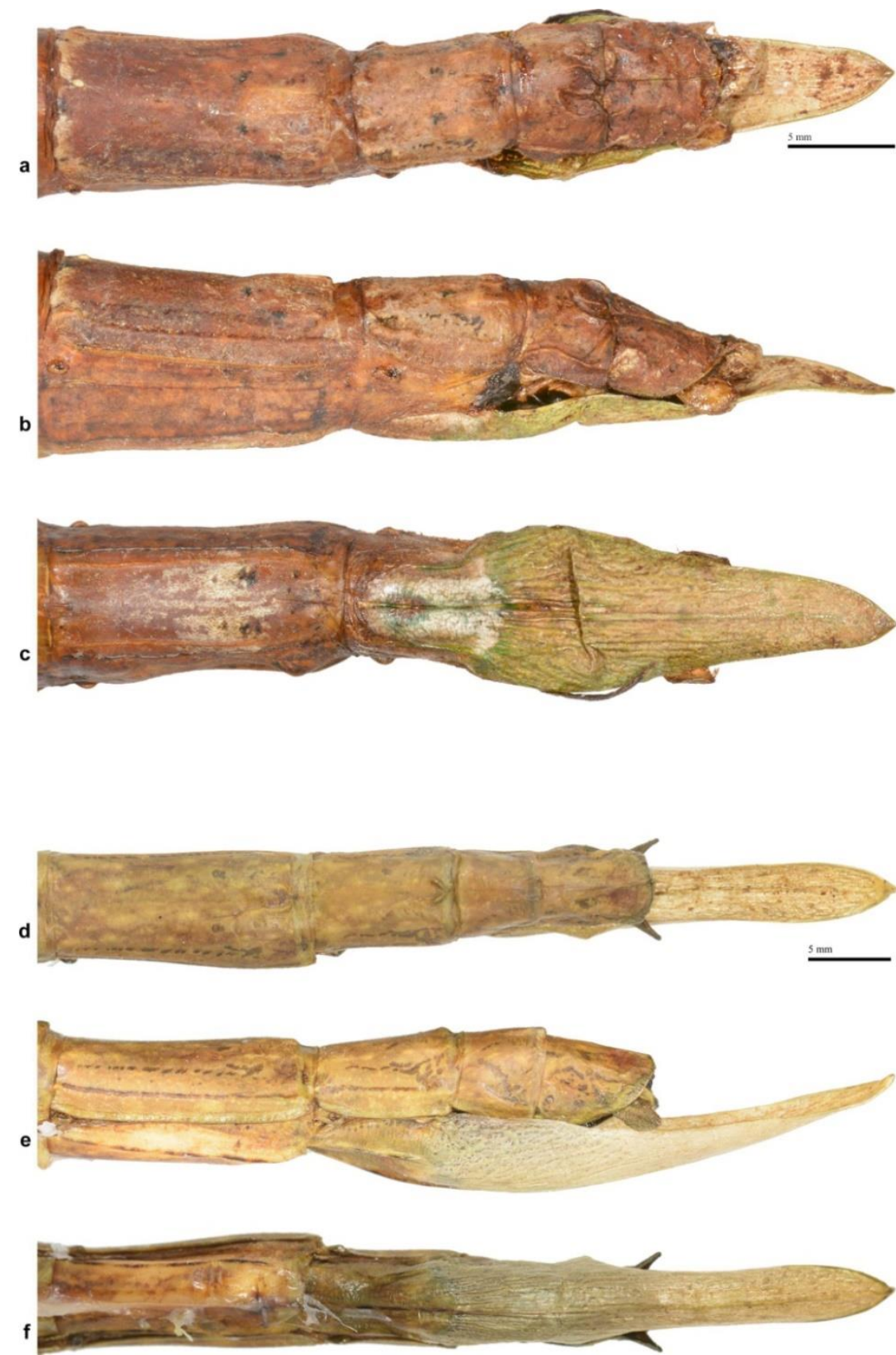

Fig. 4. End of the abdomen of a female of Acrophylla bhaskarai sp. n. (PT) and comparison with Acrophylla wuelfingi (REDTENBACHER, 1908). a-c. Acrophylla bhaskarai (PT). a. Dorsal; b. Lateral; c. Ventral. d-f. Acrophylla wuelfingi. d. Dorsal; e. Lateral; f. Ventral. 
Epiproct very small, rounded and transverse. Cerci very small, round to slightly ovate in outline, laterally compressed and hardly projecting over posterior margin of anal segment. Subgenital-plate long for the genus but not projecting over the apex of the abdomen by more than $1 / 3$; lanceolate with a fairly pointed apex, keeled longitudinally and projecting over anal segment by slightly more than the length of anal segment (Fig. 4).

\section{Male}

Fairly typical and of moderate size for the genus, with very small cerci (Fig. 5). General colouration mid brown with a slight greenish hue. Legs greenish brown with a black apical marking on femora. Head with a faint grey postocular line. Antennae pale to mid brown. Tubercles of meso- and metathorax mid to dull green. Tegmina and costal region of alae greyish pale to mid brown with all veins dull ochre, the basal portion of costal region red. Anterior margin of tegmina broadly marked with white and basal portion of alae with a longitudinal white marking along outer margin. Anal fan of alae transparent grey with all veins marked in brown. Ventral surface of costal region of alae bright red basally and gradually becoming pale reddish to ochre towards the apex (Fig. 6).

Head: About 1.3x longer than wide, gently tapering towards posterior, vertex almost flat. Eyes very large, round in outline and projecting hemispherically, their length about two times shorter than cheeks. Frons distinctly raised and with well-developed ocelli. Antennae almost reaching the posterior margin of abdominal segment II; consisting of 24 segments. Pedicellus compressed dorsoventrally, rectangular in dorsal view and about 1.3x longer than wide. Pedicellus less than half the length of scapus, cylindrical. Antennomere III longer than pedicellus, IV only $1 / 3$ the length of III. V-XIII gradually increasing in length, following antennomeres decreasing in length.

Thorax: Pronotum slightly shorter and more slender than head. Transverse median sulcus somewhat displaced towards the anterior, moderately impressed and slightly rounded. Mesothorax elongate, about $4.8 x$ longer than pronotum, slender and parallel-sided. Mesonotum with a fine longitudinal median carina and set with several very prominent, conical to bluntly spiniform green tubercles (Fig. 7). Mesosternum and metasternum also set with irregularly placed conical green tubercles, which are distinctly smaller than those of the mesonotum (Fig. 8). Tegmina lanceolate in outline, reaching about half way along median segment and with a fairly prominent roundly conical hump in anterior half. Alae somewhat variable in length but on average reaching abdominal tergum $\mathrm{V}$. 


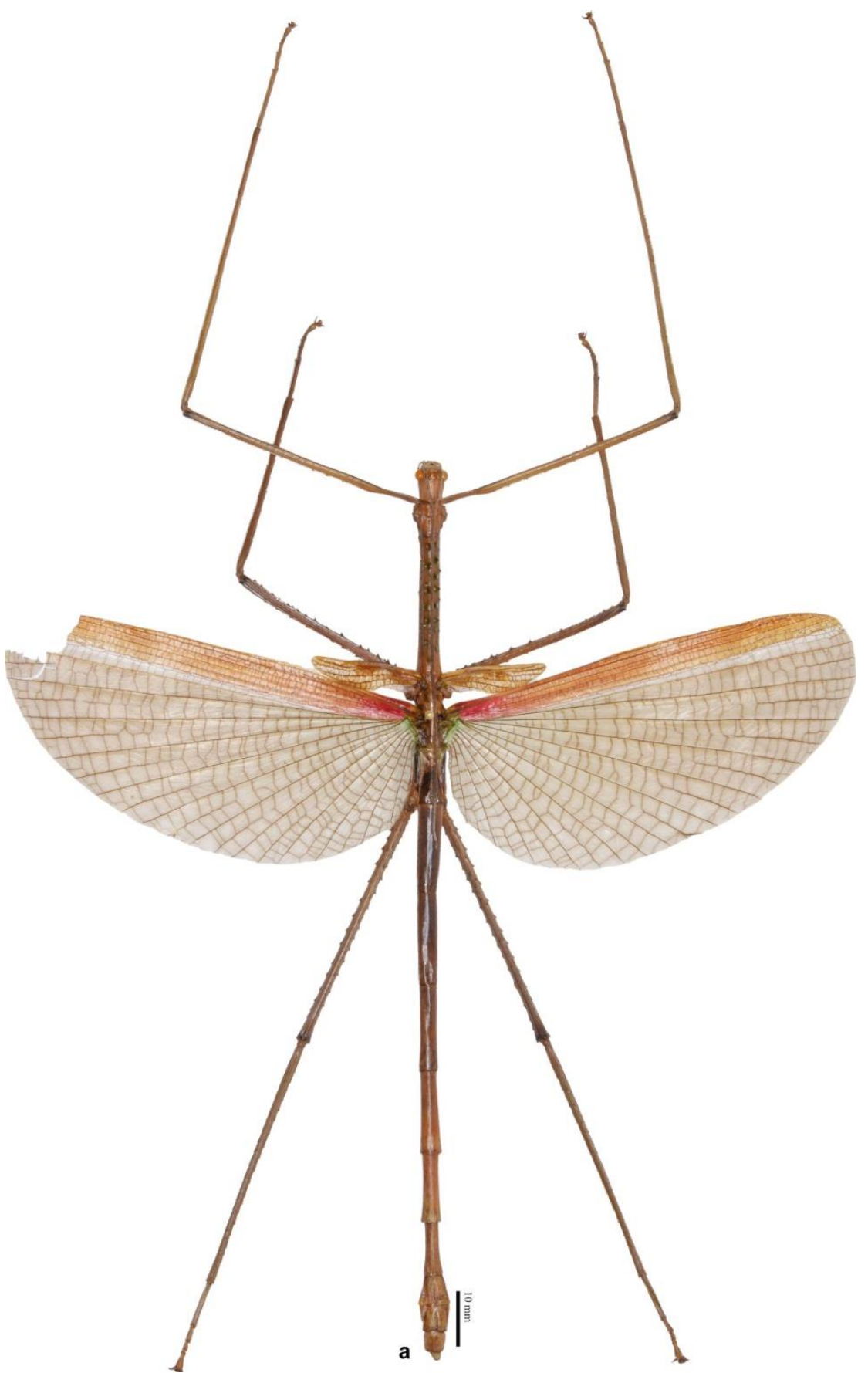

Fig. 5. Habitus of a male of Acrophylla bhaskarai sp. n. a. Acrophylla bhaskarai (PT). Dorsal. 

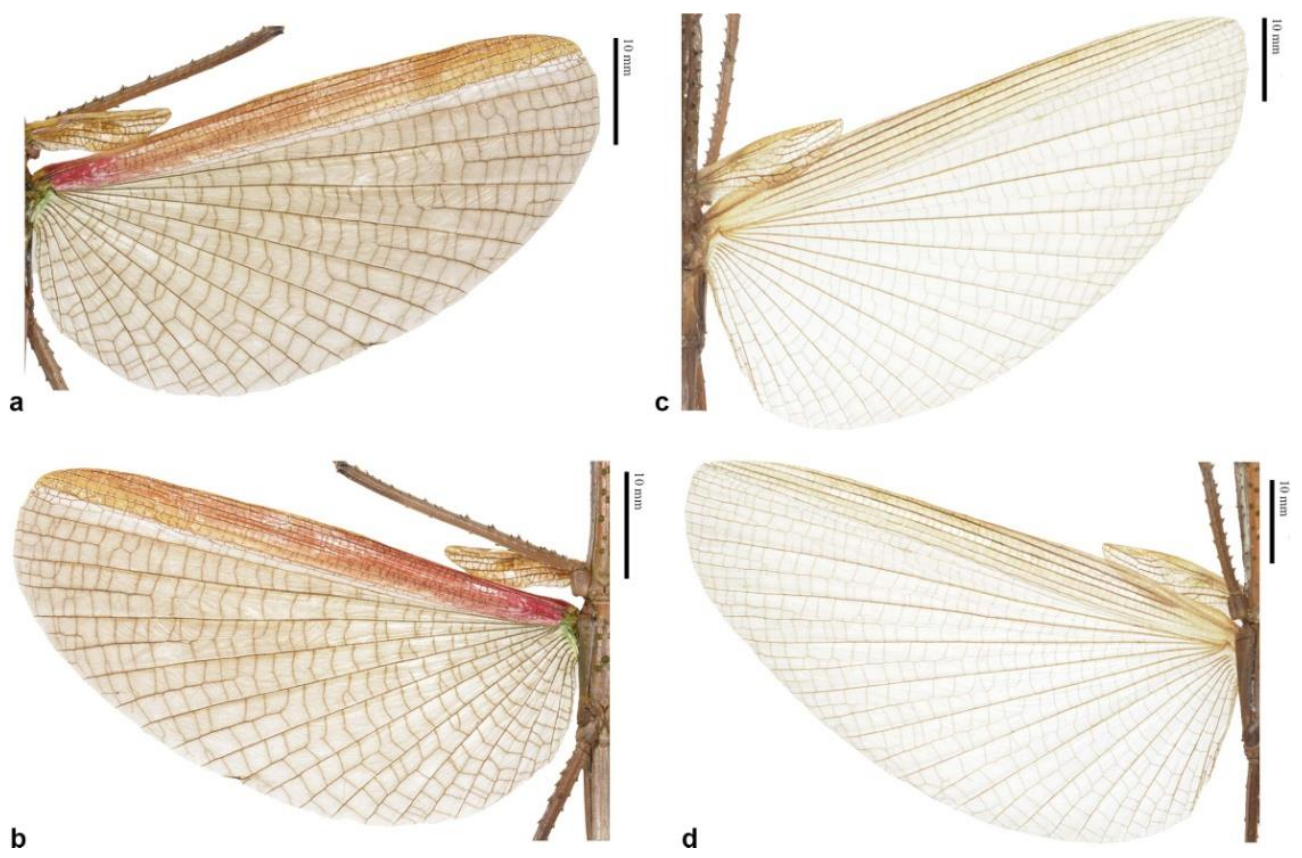

Fig. 6. Comparison of wings in males of Acrophylla wuelfingi (REDTENBACHER, 1908) and Acrophylla bhaskarai sp. n. a-b. Acrophylla bhaskarai (PT). a. Dorsal; b. Ventral. c-d. Acrophylla wuelfingi. c. Dorsal; d. Ventral.

Legs: All slender and relatively long, hind legs projecting over apex of abdomen. Mesoand metafemora with all carinae mostly serrate or dentate. Pro- and mesofemora longer than mesothorax and metafemora reaching about $3 / 4$ along abdominal segment IV. Profemora with the anterodorsal and posteroventral carinae sparsely dentate. Protibiae unarmed. Meso- and metafemora trapezoidal in cross-section, with dorsal carinae slightly approaching each other. Two outer ventral carinae distinctly dentate, the two dorsal carinae only with a few small teeth. Meso- and metatibiae with all carinae minutely serrate but the serrations less distinct on dorsal carinae. Probasitarsi elongate and considerably longer than following three tarsomeres combined; unarmed. Meso- and metabasitarsi considerably longer than the following three tarsomeres combined. See Table 1 for measurements.

Abdomen: Abdomen excluding median segment considerably longer than head and thorax combined. Segments II-VI of uniform width. II-V roughly equal in length and from $3.5 \mathrm{x}$ to $4.3 \mathrm{x}$ longer than wide; VI and VII decreasing in length; V-VII slightly widening towards posterior. Sterna II-VII all with a fine longitudinal median carina. Tergum VIII shorter than VII, trapezoidal in dorsal aspect and gradually widening towards posterior. IX about as long as VIII, strongly constricted medially and with anterior margin about $1.2 \mathrm{x}$ 
wider than posterior margin. Anal segment strongly tectiform and narrowing slightly towards posterior with the lateral surfaces slightly deflexed in anterior portion. Epiproct very small, hardly visible in dorsal aspect. Poculum small, convex, cup-shaped and carinate longitudinally in apical portion; the posterior margin narrowed and slightly labiate. Cerci very small, hardly equal in length to anal segment, oval in outline and laterally compressed (Fig. 9).

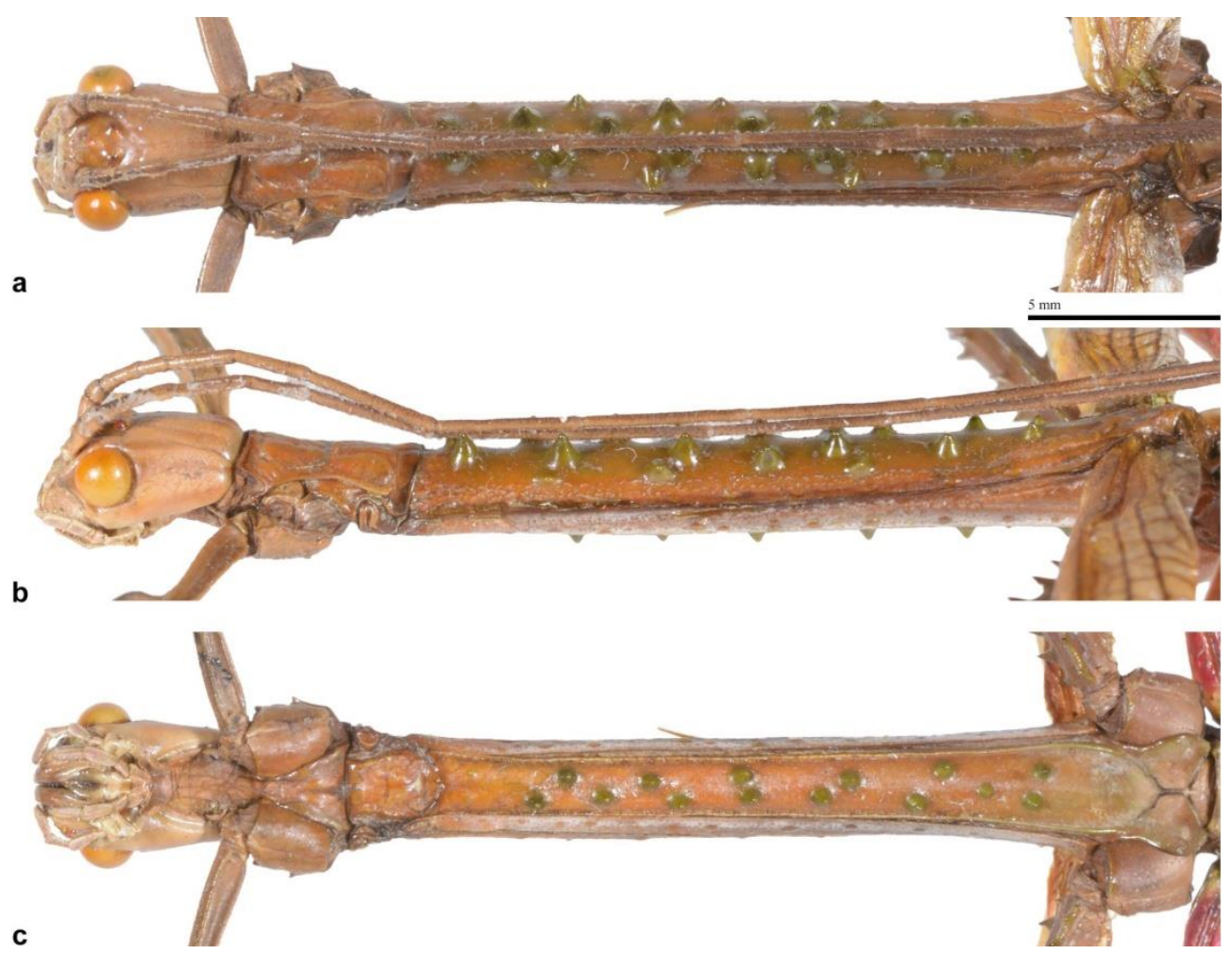

Fig. 7. Head, prothorax and metathorax of a male of Acrophylla bhaskarai sp. n. a-b. Acrophylla bhaskarai (PT). a. Dorsal; b. Lateral, c. Ventral. 


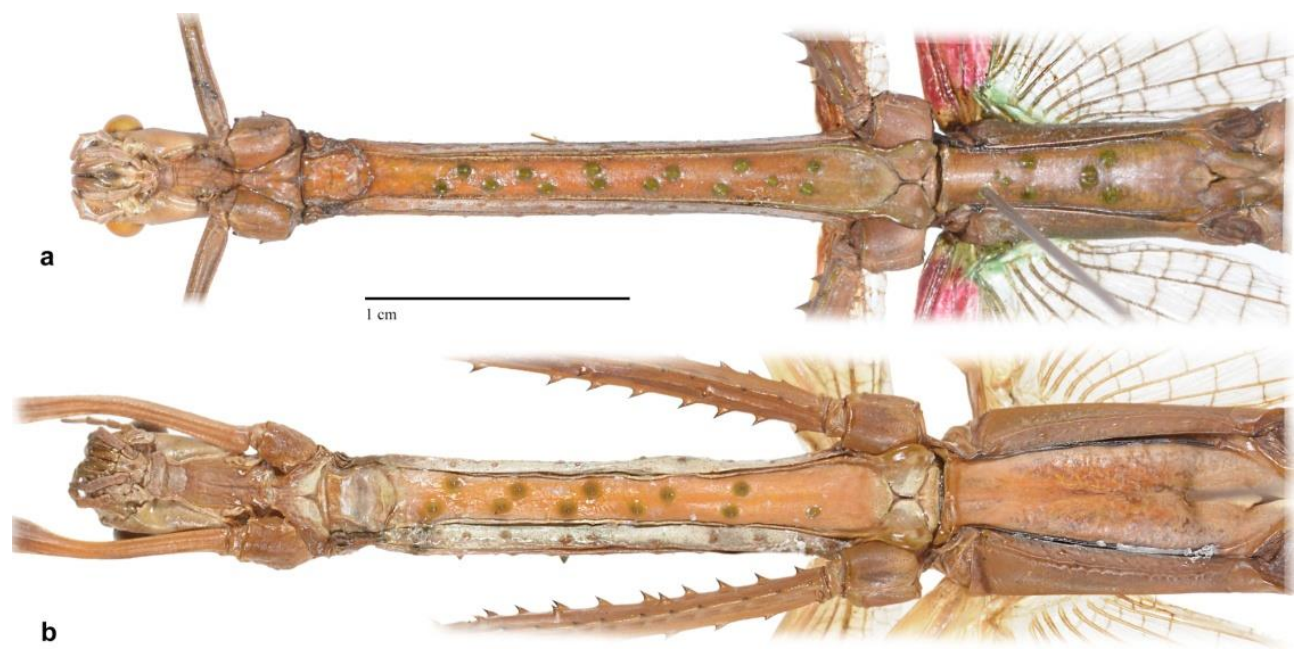

Fig. 8. Mesosternum and metasternum: comparison in males of Acrophylla wuelfingi (REDTENBACHER, 1908) and Acrophylla bhaskarai sp. n. a. Acrophylla bhaskarai (PT). Ventral. b. Acrophylla wuelfingi. Ventral.

\section{Egg}

Capsule elongate, about $1.5 x$ longer than high, compressed laterally with the crosssection distinctly oval and gently curved in lateral aspect; dorsal surface strongly convex and bulging longitudinally (Fig. 2 c-e). Posterior portion somewhat narrowed and polararea with a distinct mound. Entire surface of capsule and operculum finely punctured. Micropylar plate slender, elongate, almost parallel-sided with the posterior end strongly laterally deflexed to form an almost circular lobe on each side. Micropylar cup distinct and placed near posterior end of plate and formed by a blunt, C-shaped ridge with a shallow impression in the centre. Operculum flat and almost round. Owing to the small number of available eggs and the capitulum being damaged in most of them, it is not possible to give a proper description of this structure. See Table 1 for measurements.

\section{Variability}

This species seems to be much less variable than A. wuelfingi (REDTENBACHER, 1908), although the small number of known specimens does not allow a definitive judgement to be made on the full range of variability of A. bhaskarai sp. n. Based on the specimens to hand, variability is only seen in the size, colouration of the body and wings, and number of granules of the mesonotum. 


\section{a}

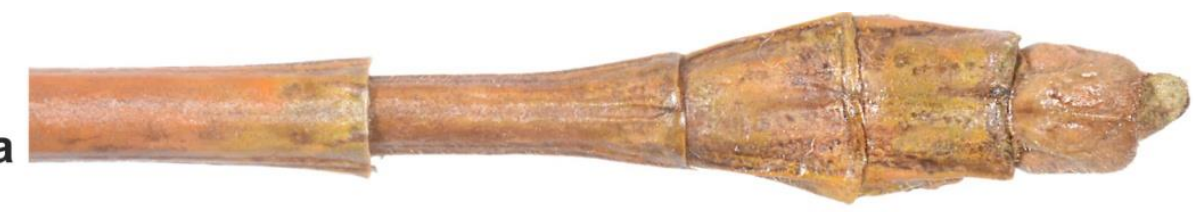

b

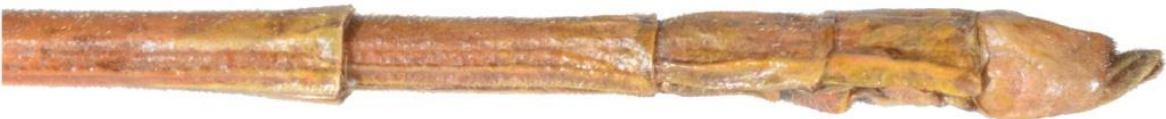

C

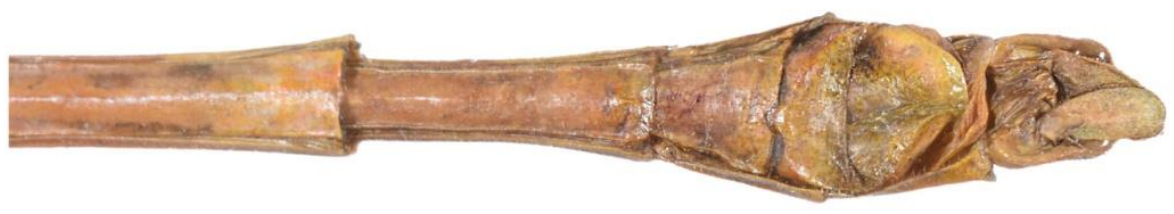

d
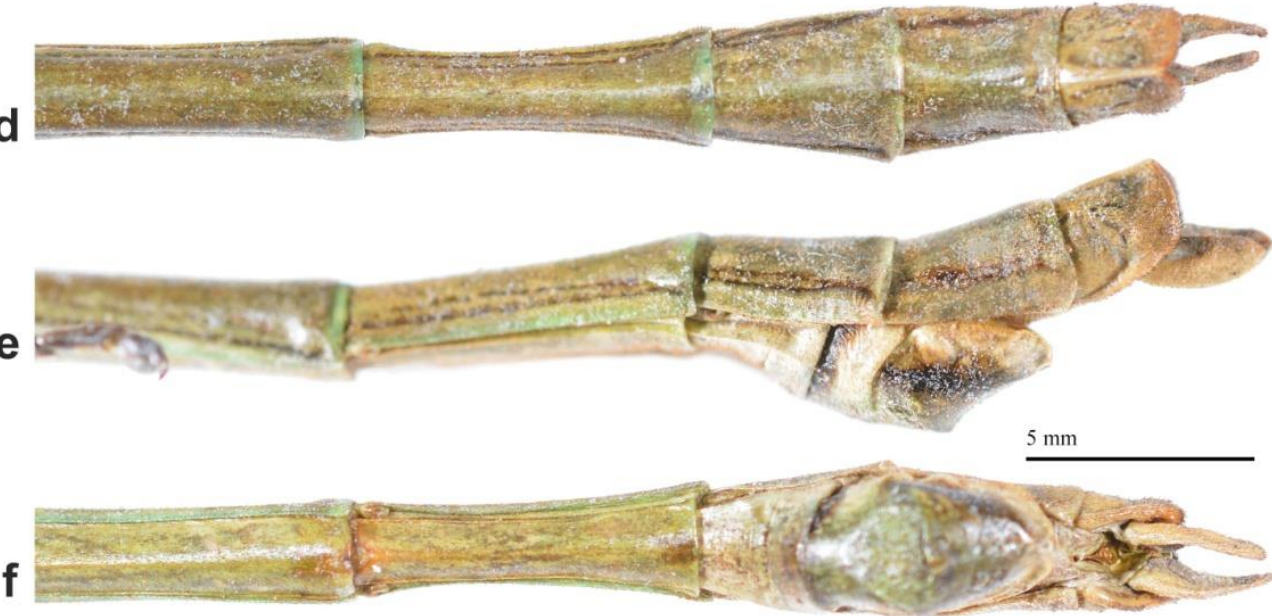

Fig. 9. End of the abdomen of a male of Acrophylla bhaskarai sp. n. and comparison with Acrophylla wuelfingi (REDTENBACHER, 1908). a-c. Acrophylla bhaskarai (PT). a. Dorsal; b. Lateral; c. Ventral. d-f. Acrophylla wuelfingi. d. Dorsal; e. Lateral; f. Ventral.

\section{Distribution}

So far only recorded from Larat Island, the northernmost of the Tanimbar Islands, in the Province of Maluku in south-eastern Indonesia. See distribution map (Fig. 10). 


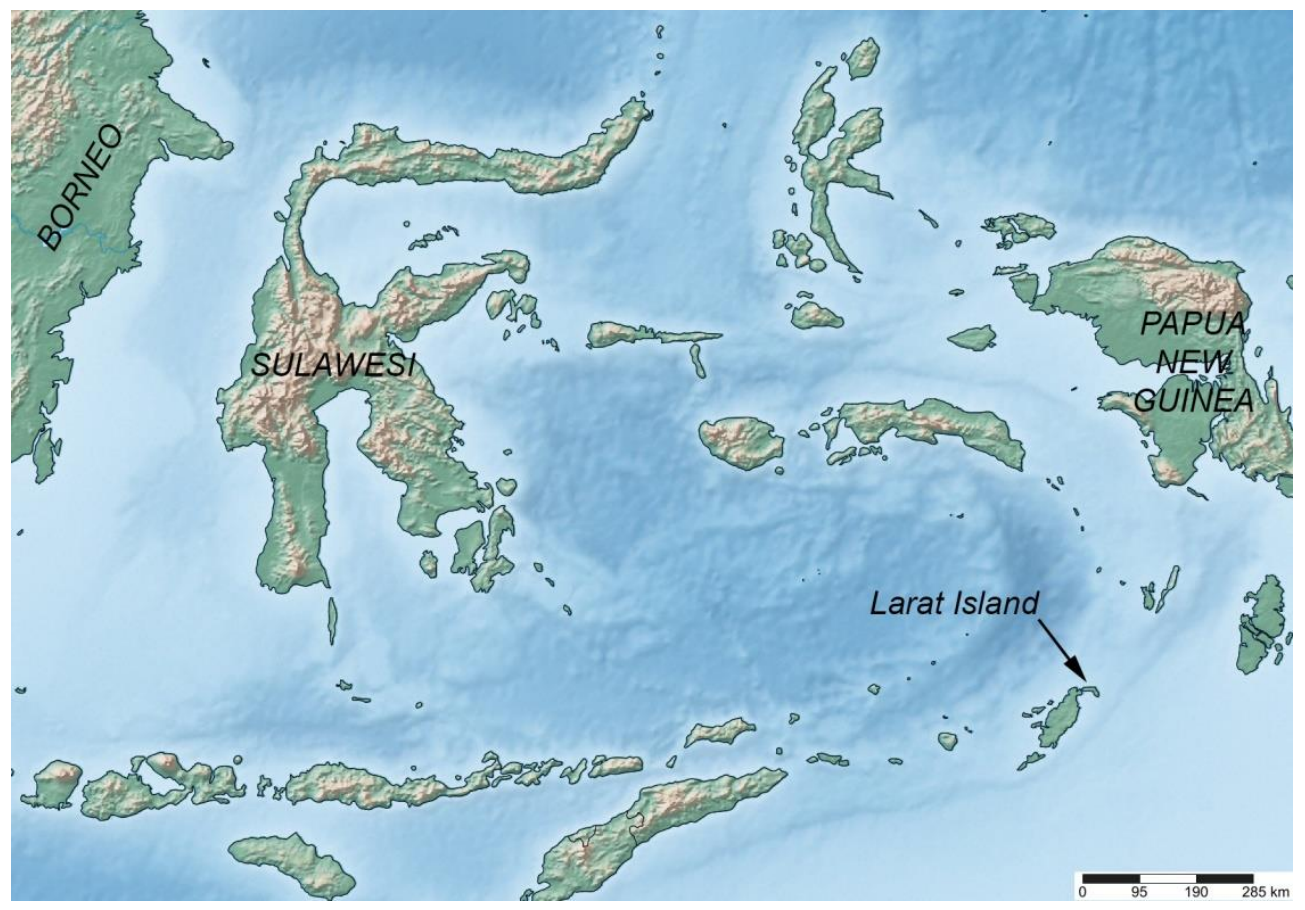

Fig. 10. Distribution map. Larat Island in Wallacea.

\section{CONCLUSIONS}

The species newly described here is the first representative of the genus Acrophylla GRAY, 1835 recorded from Wallacea and raises the number of genera of the tribe Phasmatini GRAY, 1835 in this particular region to five and the number of species to nine (see checklist below). The discovery of a species of Acrophylla in the extreme south-east of Wallacea emphasises the strong influence of Australian biota in Wallacea, since it is the third principally Australian genus of Phasmatini to have representatives in Wallacea. The other two genera that have species in Australia and Wallacea are Anchiale STÅL, 1875 and Eurycnema SERVILLE, 1838 (HENNEMANN et al. 2015). Interestingly the most similar and presumably most closely related species of A. bhaskarai sp. n. is A. wuelfingi (REDTENBACHER, 1908), which has a fairly restricted distribution in northern Queensland (BROCK \& HASENPUSCH 2009: 95). The mechanisms which led to the occurrence of $A$. bhaskarai sp. n. on Larat Island are not known and any broader discussion would be highly speculative. 
An updated checklist of species of the tribe Phasmatini that occur in Wallacea is presented below:

Genus Acrophylla GRAY, 1835: 38.

Acrophylla bhaskarai sp. n.

Genus Anchiale STÅL, 1875: 36, 84.

Anchiale buruense HeNNEMANn, CONLE \& SUZUKI, 2015: 13.

Anchiale maculata (OLIVIER, 1792: 636).

Genus Eurycnema AUDINET-SERVILLE, 1838: 235.

Eurycnema nigrospinosa REDTENBACHER, 1908: 469.

Eurycnema versirubra (AUDINET-SERVILLE, 1838: 235).

Genus Paracyphocrania REDTENBACHER, 1908: 466.

Paracyphocrania lativentris REDTENBACHER, 1908: 466.

Paracyphocrania major HENNEMANN, CONLE \& SUZUKI, 2015: 42.

Genus Phasma LICHTENSTEIN, 1796: 77.

Phasma gigas (LINNAEUS, 1758: 425).

Phasma marosense HENNEMANN, 1998: 117.

\section{REFERENCES}

Brock P.D., HasenPusch J. 2007. Studies on the Australian stick insects (Phasmida), including a checklist of species and bibliography. Zootaxa 1570: $1-81$.

BRock P.D., Hasenpusch J. 2009. The Complete Field Guide to Stick and Leaf Insects of Australia. CSIRO Publishing, Collingwood.

CHEN S.C., HE Y.H. 2001. Two new record genera and new species of Phasmatodea from China (Phasmatodea: Phasmatidae, Heteronemiidae): Entomological Journal of East China 10(1): 8-10.

Chen S.C., He Y.H. 2008. Phasmatodea of China. China Forestry Publishing House, Beijing.

Clark-SELliCK J.T. 1997. Descriptive terminology of the phasmid egg capsule, with an extended key to the phasmid genera based on egg structure. Systematic Entomology 22(2): 97-122.

Hennemann F.H., Conle O.V., SuzuKi S. 2015. A study of the members of the tribe Phasmatini GRAY, 1835, that occur within the boundaries of Wallacea (Phasmatodea: Phasmatidae: Phasmatinae: "Lanceocercata"). Zootaxa 4008(1): 1-74.

Hennemann F.H., Conle O.V., Zhang W. 2008. Catalogue of the Stick and Leaf-insects (Phasmatodea) of China, with a faunistic analysis, review of recent ecological and biological studies and bibliography (Insecta: Orthoptera: Phasmatodea). Zootaxa 1735: 1-76.

KIRBY W.F. 1904. A synonymic catalogue of Orthoptera. 1. Orthoptera Euplexoptera, Cursoria et Gressoria. (Forficulidae, Hemimeridae, Blattidae, Mantidae, Phasmidae). The Trustees of the British Museum, London 1: 1-501. 
Redtenbacher J. 1908. Die Insektenfamilie der Phasmiden, III. Phasmidae Anareolatae (Phibalosomini, Acrophyllini, Necrosciini). Verlag Engelmann, Leipzig.

Received: 30 November 2017

Accepted: 26 January 2018 